\title{
A closer look at familial Mediterranean fever cases in a large breast cancer dataset
}

\author{
Kadri Altundag ${ }^{1}$ (D)
}

Received: 27 April 2019 / Accepted: 3 June 2019 / Published online: 5 June 2019

(c) Springer-Verlag GmbH Germany, part of Springer Nature 2019

Dear editor,

I want to congratulate Bilgin and their colleagues for their article [1] in which they evaluated cancer incidence among 3899 familial Mediterranean fever (FMF) patients with or without amyloidosis. Thirty-eight patients were diagnosed with cancer during follow-up. The most common cancer was breast cancer in females (7/28 patients) and leukemia ( $2 / 10$ patients) in males. Median age at the diagnosis of cancer was 50 years. Study by Bilgin et al [1] was one of the largest study showing cancer incidence in FMF patients. This study had several limitations. Patients diagnosed with cancer out of this institution might have been documented. Since median age of whole population was 22 and median follow-up duration of these patients was 81 months, number of expected cancer cases would increase with longer followup. They did not have any data regarding the distribution of other factors that affect the cancer risk among FMF patients (for example, hormonal risk factors, family history, and body mass index for breast cancer cases). The authors did not give detailed information about cancer types, specifically breast cancer. From my own breast cancer data set including 6117 invasive breast cancer patients diagnosed between years of 2006-2019 in a tertiary care setting, 16 breast cancer patients had a history of FMF. Median age at the diagnosis of breast cancer in FMF patients was 46. Interestingly, 50\% and $25 \%$ of 16 patients had luminal B and HER-2 positive subtypes, respectively. In our recent study [2], we found that a total of $66.3 \%(n=1249)$ of the breast cancer patients had luminal A, $12.4 \%(n=234)$ had luminal B, $9.0 \%(n=169)$ had HER2 overexpressing, and $12.3 \%(n=232)$ had triple negative breast cancer. Compared to our general breast cancer cohort, FMF patients with breast cancer seem to have more aggressive pathological characteristics (more luminal B and HER-2 + cases). Second, compared to median age of all cancers developed in FMF group, median age of breast cancer in FMF patients seems to be younger However, it is not appropriate to make a conclusion about the effect of FMF on breast cancer based on the data of with only 16 patients. My data might give an idea that breast cancers developed during FMF might show different biological subtypes and should be investigated in larger multi-institutional studies with longer follow-up with detailed drug information and and risk factors that might affect breast cancer risk

\section{References}

1. Bilgin E, Dizdar Ö, Güven DC, Ceylan S, Aybi Ö, Aybi Ö, Furlatan B, Kardaş RC, Kardaş RC, Yıldırım T, Hayran MK, Hayran MK, Kalyoncu U, Özen S, Özen S (2019) Cancer incidence in familial Mediterranean fever patients: a retrospective analysis from central Anatolia. Rheumatol Int. https://doi.org/10.1007/s00296-01904311-x

2. Turkoz FP, Solak M, Petekkaya I, Keskin O, Kertmen N, Sarici F, Arik Z, Babacan T, Ozisik Y, Altundag K (2013) Association between common risk factors and molecular subtypes in breast cancer patients. Breast 22(3):344-350. https://doi.org/10.1016/j. breast.2012.08.005 (Epub 2012 Sep 14)

Publisher's Note Springer Nature remains neutral with regard to jurisdictional claims in published maps and institutional affiliations.
Kadri Altundag

altundag66@yahoo.com

1 MKA Breast Cancer Clinic, Tepe Prime, Cankaya, 06800 Ankara, Turkey 